\title{
The Designing of Junior High School Online English Listening Test in ITS
}

\author{
Wan Liu \\ School of Foreign Languages \\ Yibin University \\ China \\ 771644375@qq.com
}

\author{
Jia Ruan \\ School of Foreign Languages \\ Yibin University \\ China \\ 1464335845@qq.com
}

\begin{abstract}
In the context of the development of education informationization, online test system is a teaching method to adapt to the education informationization development trend under the intelligent tutoring system (ITS), but at present, traditional listening test exists the issues of untimely feedback and lack of interaction, therefore, this paper from the introduction of ITS, as well as based on the analysis of English listening test in junior high school, introduces the Moodle online test platform which used behaviorism, constructivism and humanistic theory, ITS as the basis, and focuses on designing junior high school online English listening test in Moodle platform, by taking advantage of Moodle's modules caused the enthusiasm of students, and then assisted deficiencies of conventional listening tests, ultimately, designing an intelligent online examination system based on Web, it will achieve the establishment of database, on-line test, automatic marking scores and other functions, to solve the issues of junior high school students listening level is generally not high and listening test untimely feedback, lack of interactivity in listening test. Because of the limited writing space, sparse shallow owns scholarship essays. Certainly there are many shortcomings and needs more in-depth study.
\end{abstract}

Keywords : ITS; Junior High School English Listening; Online Test Design; Moodle

\section{INTRODUCTION}

At present, most of junior high school English listening tests are still using the traditional method for testing by paper. The traditional listening test still exists the problems of untimely feedback and lack of interactivity. The traditional listening test not only fails to provide the appropriate guidance which conforms to the character of learner's and realizes the personalized test, but also fails to adapt to the needs of the development of the current education informatization. However, the disadvantages can be solved by ITS.

The research on ITS began in the early 1970s, Jaine Carbonell, Allan Collins Bolt Neranek Newman's Jaine Carbonell, Allan Collins Scholar jointly developed system is considered to be the first ITS[1]. After the 1990s, with the development of intelligent learning environments and ITS development tool of research, teaching and research intelligence continues to move forward [2]. Compared with developed countries, the domestic ITS research started relatively late in China. In theory still reference the results of foreign-based research work mainly in a few universities and research institutions [3].

At the same time, with the analysis of junior high school English listening test and based on the introduction of ITS, this paper introduces the Moodle platform which is based on the ITS. Then the paper focuses on how to use the function module of Moodle platform to design the online English listening test in junior high school, and then to assist the traditional English listening test. Finally, designing an intelligent online examination platform, which based on the web, can achieve the function of establishing database, online examination, automatic scoring, etc. The purpose of this paper is to solve the problems of students' lower listening level, the results of the listening test untimely feedback, and the lack of interactive in junior high school listening test.

\section{LITERATURE REVIEW}

\section{A. Analysis of Listening Test in Junior High School}

1) Characteristics of English Listening Test in Junior High School

"Listening, speaking, reading and writing are the basic facets tested in a language test. Due to its unparalleled position, listening test changes dramatically" [4]. Therefore, English listening test in junior high school has the following characteristics:

a) Flexibility. It is not only to test students how to understand the language and more importantly is to test students listening comprehension ability in a real communication situation by imitating conversations in different situations.

b) Practical. It focuses on training students' to use "listening".

c) Timeliness. Listening training requires students not only make a timely response to the sound signal. But also with accurate understanding and memory make timely feedback for the listening content. 


\section{School}

2) Problems of English Listening Test in Junior High

Currently, English listening test in junior high school is mainly in the form of examination. The test ignore the cultivation of communicative ability, listening comprehension has become the weak link. Therefore, the main problems in English listening test of junior high school are as follows:

a) Lack of interaction. The traditional listening test use the way of listen to the answer. This is a single test model and lack of interactive. So, it is difficult to improve students' learning motivation.

b) Untimely Feedback. Using the traditional paper listening tests, students can not gets the test feedback immediately, teachers can not gives students the scientific guidance in time. So, it affects the efficiency of listening teaching.

c) Lack of real learning situation. For the difficult contents, teachers use the way of lets the students read the listening material, instead of the real environment. So, it can not stimulate students' interest in learning.

\section{B. Introduction of ITS}

\section{1) Definition of ITS}

Intelligent tutoring system (ITS) is an adaptive learning system with the help of artificial intelligence technology to let the computer play the role of teachers in implementing individualized teaching, provide guidance to the different requirements and characteristics of learners' knowledge [6].

\section{2) Structure of ITS}

The description of system structure about ITS, in fact, is the division of internal to the system module.

a) Domain expert module (Domain Knowledge): It is the module that is used to determine the teaching content and teaching objectives.

b) Student model module: System understands student through the student module.

c) Teacher model module (Teaching Strategy): This module under the guidance of a certain teaching principle, with the appropriate expression forms shows students at the right moment.

d) Intelligent Interface: This module is a component which is the system and user interaction.

\section{3) Characteristics of ITS}

In view of the present problems in the junior high school English listening test, therefore determines ITS will show the following basic features:

a) Personalization. Personalized system is reflected in its focus on one to one relationship between teachers and students, according to different students' cognitive characteristics to implement individualized instruction [6].

b) Autonomy. This feature performance at the system can dynamically understand the students' learning state.

c) Intelligent. The system diagnoses students' errors, analyses the causes and corrects mistakes in time.

\section{Theoretical Basis of this System}

1) Introduction of Behaviorism Theory and Constructivism Theory

Russian scientist Pavlov is the representative of behaviorism learning theory. According to the theory, language learning follows the process of stimulus response, which can be seen as an influence that is constantly being influenced by external stimuli and eventually becomes a habit and consolidated.

Constructivism is an important branch of cognitive learning theory. The theory advocates inquiry teaching model that teaching should regard the "learning" as the center, pay attention to students' initiative, enthusiasm and construction [6].

\section{2) Humanistic Learning Theory}

The humanistic learning theory points out that the essence of learning is forming and gaining experience. The learning process is the process of experience [7]. Humanistic learning theory representative, Maslow and Rogers, their views emphasize students' autonomous and collaborative learning. The theory holds the point that students' interest is treated as the guidance of teaching designing, which lets the students learn to solve problems initiatively, meeting the needs of the students' self-realization:

Humanistic theory and constructivism theory, however, the difference is more emphasis on humanistic theory "People oriented", focus on student's individual differences and values [7].

\section{TeChNiCAL SUPPORT OF THIS TEST}

\section{A. Introduction of Moodle Platform}

Moodle (Modular Object - Oriented Dynamic Learning Situation) is a free open source course management system (CMS) which develops by Australian teacher Martin Dougiamas based on constructivism education theory [8].

Moodle presents teachers and students such a platform which under the theory of social constructivism. It has the characteristics of fairness and interactivity, offers the majority of students in a learning situation with explorer, autonomous learning and collaborative learning [9].

\section{B. Main Function of Moodle}

\section{1) Learning Tracking}

The administrator or teacher can set the basic attribution and specific content of courses. Teachers can set listening test according to the content of the class. Under the condition of editing, teachers can edit the content of the course, such as "adding activities", etc. Teachers can upload the learning resources in course content, such as websites, video, documents. Teachers can also design listening tests according to students' different level of listening with different levels of difficulty, so as to achieve the effect of testing students in accordance with their aptitude.

\section{2) Collaborative Communication}

After teachers use Moodle platform to set learning tasks, students can learn by group cooperation model to complete 
tasks so that it makes individual knowledge of meaningful structure come true. In the editing, teachers can use the function of course management and discussion module so that teachers and students, students and students can communicate with each other, which fully develops the initiative of students. "The children are actively putting forward ideas and testing them against one another's ideas before submitting them to the computer"[9]. Teachers can find problems in time, and help students to solve them.

\section{3) Test Management Function}

The following is a management module of the test method of use of a simple introduction:

a) Creating a new test at first includes the name of test, the character of the examination, the test time, the test requirements, the grading standards, the password and the test results of the examination way of feedback, etc.

b) Putting the new test into item can be the test question types, a total of 12 kinds of questions.

c) Selecting the desired topic is from the current test and the composition of a piece of paper.

d) Students have the prescribed time for reply.

e) After the test, the score automatically appears.

f) The teacher can view the students' test scores.

\section{Online Test Design of English Listening in Junior High SCHOOL BASEd ON MOODLE}

\section{A. Basic Requirements of Online Test}

Teachers need to pay attention to the following points when they design online testing of listening:

Firstly, the design of test should consider the differences of individuals. Secondly, in the stage of listening comprehension, teachers should enhance the interactivity of class. At the same time, the teacher gives the timely guidance to the students' learning process :

"In a feedback session, the teacher and students check and discuss the responses to the while-listening task. The teacher's role is to help students see how successful they have been in doing task'[10].

\section{B. Analysis and Determination of the Content of the Test}

New curriculum standards for junior high school students' English listening skills pay more attention to train the listening and speaking abilities. According to the requirements of the new curriculum standards for the designing of listening teaching, teachers should pay attention to students' learning the pronunciation, vocabulary, syntax and understanding of the situation dialogues. Therefore, when teachers design the online listening test, they should choose the listening material in the form of dialogue.

\section{Design and Application}

\section{1) Set a New Test}

The role of the test module is to provide online test and computer automatic marking. When the content of listening test has been identified, the teacher is the core task of the production online test.

First, teachers find the audio of this listening test on webpage. Then the teacher enters the question bank of this test on Moodle platform, and sets up a new descriptive question in the question bank.

a) Click the "Add activity" to select the "Online test" in the drop-down menu, as show in fig.1:

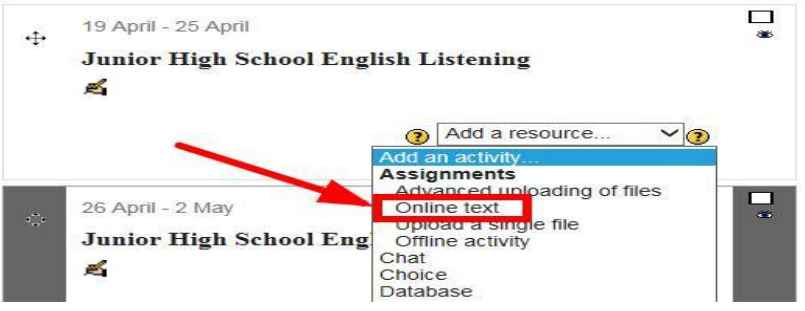

Fig.1. Add an activity

b) To enter the edit page test, in which the name of the test set up test, the start time and the end time of the test, and then the test name will be displayed on the course page, as show in fig. 2 , fig.3and fig. 4 :

Updating Assignment in 19 April - 25 April(3)

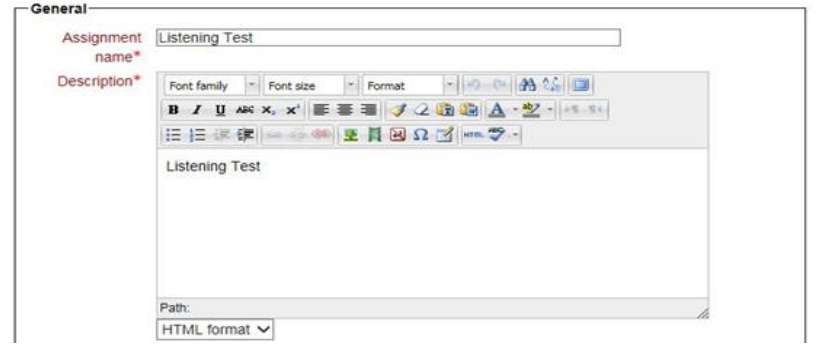

Fig.2. The name of the test

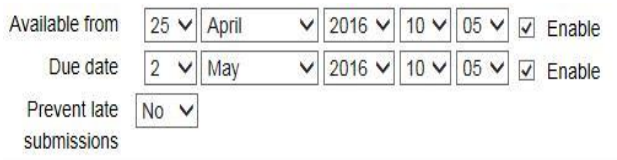

Fig.3. The start time and the end time of the test

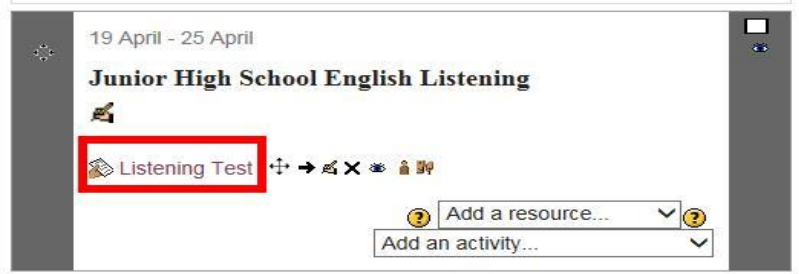

Fig.4. The test name

2) Code of the Listening Test

After entering the editorial page of descriptive question, click the "HTML" icon of 'question text' field, and then enter the listening source code of the editor. As show in fig.5 and fig.6: 


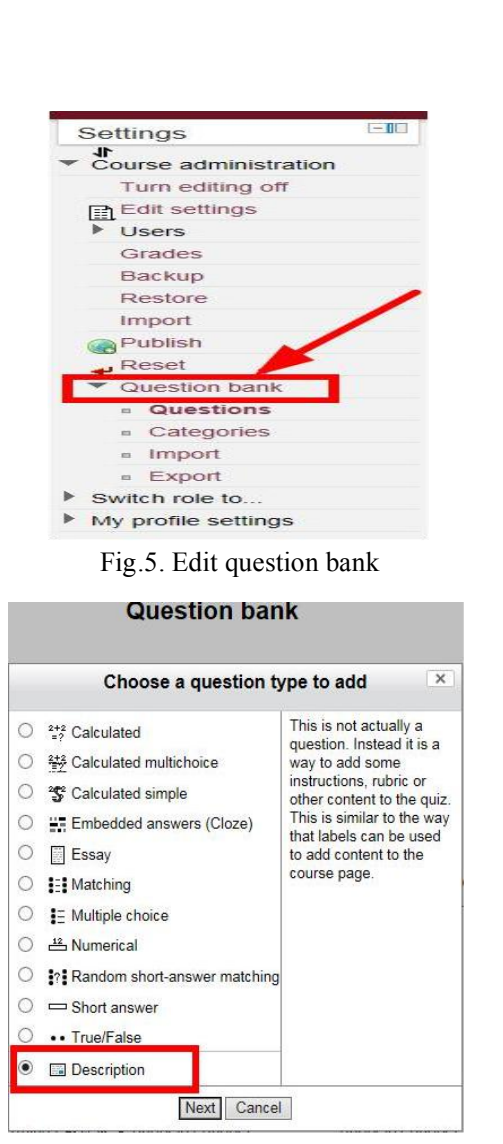

Fig.6. Choose a question type to add

3) Code of the Listening Test

After entering the problem description edit page, in the "question text" toolbar, click "HTML" icon in the source editor listening, the listening test audio URL pasted on listening the source code editor. Edit listening code needs to follow the syntax of some of the provisions; the following is the basic syntax of HTML, as shown in fig.7:

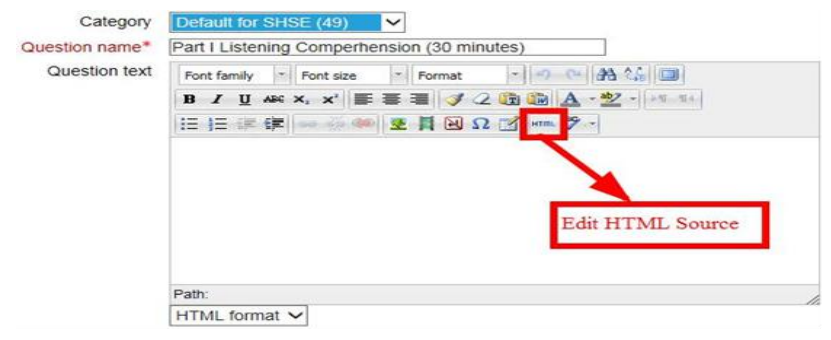

Fig.7. Edit HTML source

As described above fig. $8,<\mathrm{html}>$ and $</ \mathrm{html}>$ tags defines the start and the end of the document, between them is the beginning of the document with the main body, $<$ head $>$ tag represent the top of the document, $<$ title $>$ tag represent the title of the document, $<$ body $>$ tag represent the main body, teachers can add the listening test text here.

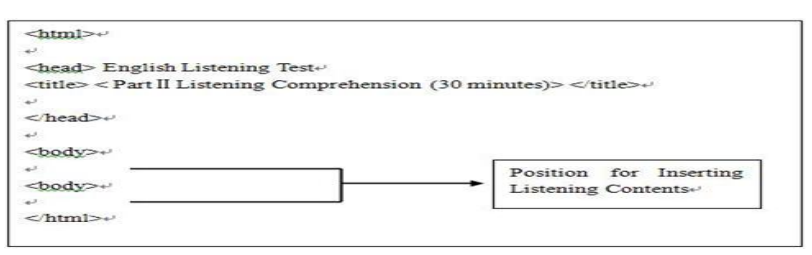

Fig.8. The basic syntax of HTML

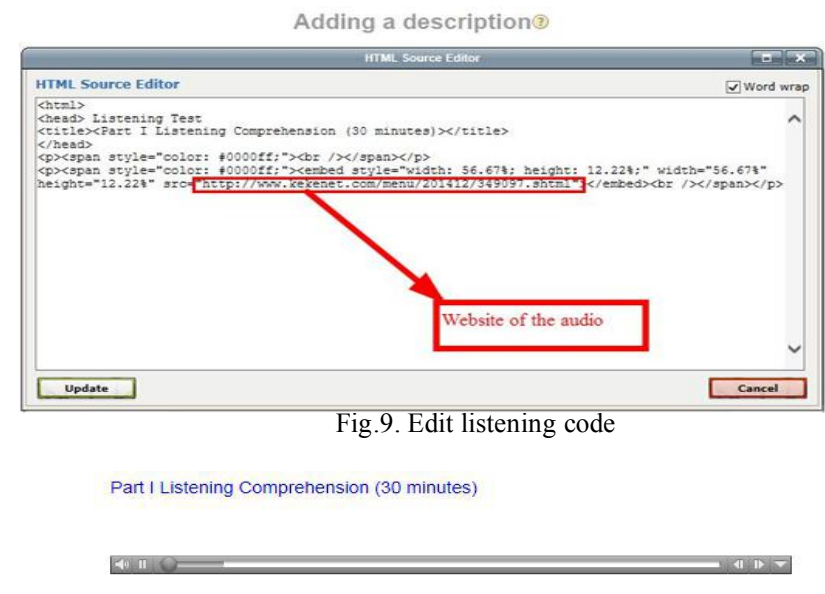

Fig.10. Listening player

\section{4) Multiple-choice in Listening Test}

Multiple-choice tests are fast, easy, and economical to score. In fact, they are machine scorable [11]. Multiple-choice is one of the main types in Junior high school English listening test, and multiple-choice in Moodle platform is an ideally suitable type for junior high school English listening test. The following is a detailed procedure for the preparation of multiple-choice:

a) Enter the question bank, select the "choice" in the drop-down menu of "Create a new question", as show in fig.11:

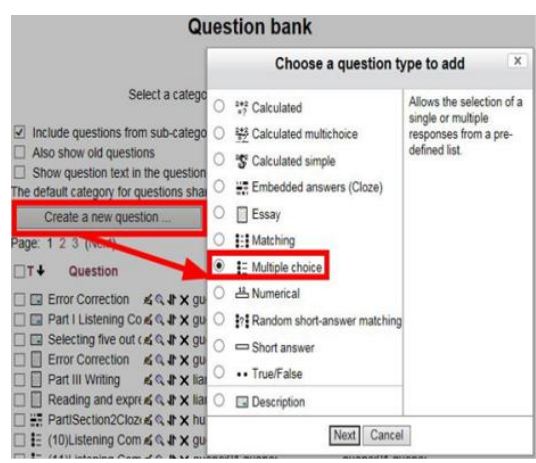

Fig.11. Sets up a multiple choice

b) Fill the question name and question text in editing page of multiple-choice, as shown in fig.12:

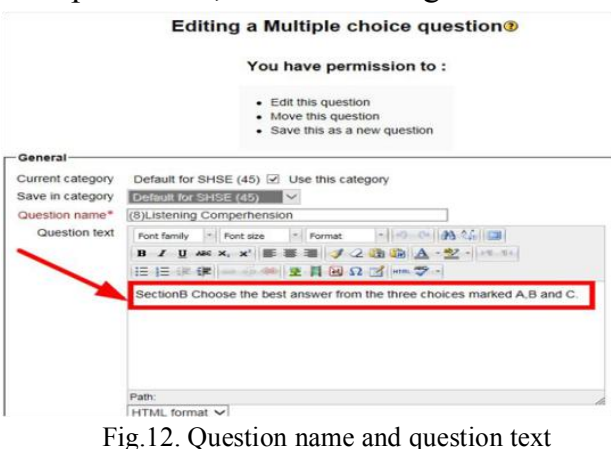

c) Set up the general feedback, as long as the students to submit answers, there will be a feedback, as show in fig.13: 


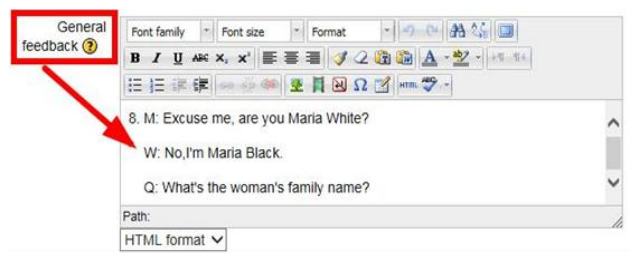

Fig.13. General feedback

d) Set the answer options, as show in fig.14:

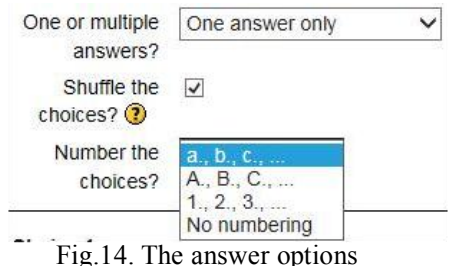

e) The correct answer in the "score" drop-down menu, choice "100\%", whereas the wrong option to choice "None" in the drop-down menu, as shown in fig. 15 and fig.16:

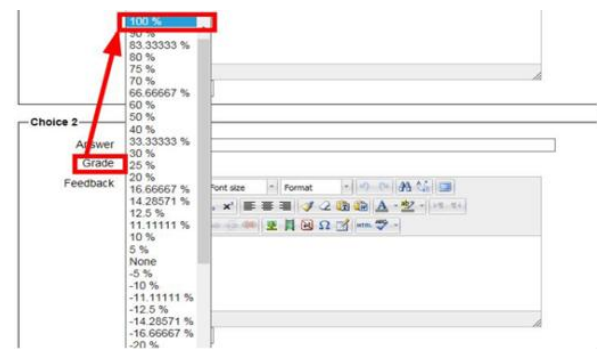

Fig.15. The grade of right answer

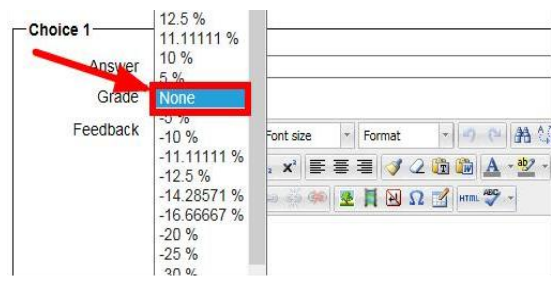

Fig.16. The grade of wrong answer

f) Click the "Save Changes", thia multiple-choice is designed, as show in fig.17:

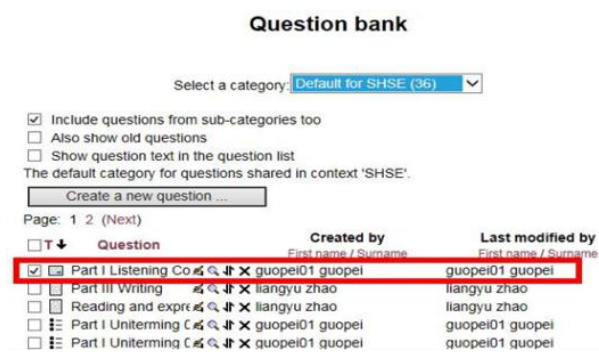

Fig.17. The multiple-choice in question bank

g) Lick the preview icon $\Omega$, students can try to answer, test interface shown in fig.18:

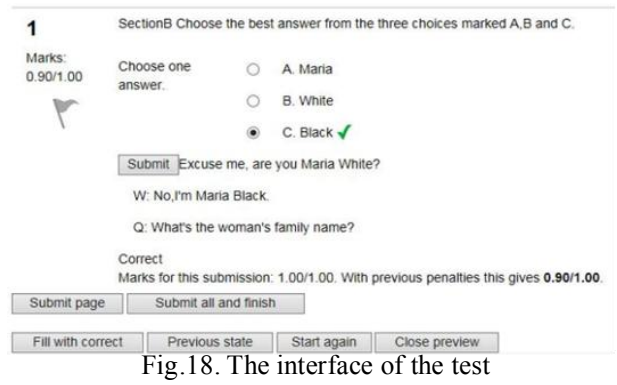

Compared with the traditional listening tests, using the Moodle platform to design online test has great advantages. By using the function module of Moodle platform to design online listening test, the function of the timely feedback gives a well solution to the problems existing in the traditional listening tests and improve the interactivity of the listening test. At the same time, teachers can increase or decrease the question in question bank, thus to help the poor students to solve the listening difficulties from the understanding of vocabulary, syntax and situational dialogues in targeted intensive training. To some extent, this satisfaction the learning needs of students and the design requirements of the test contents.

\section{Conclusion}

In this paper, the teacher design the test by using activity module of Moodle platform to design the test, which is to set up a knowledge management promotion platform for students. The platform not only can realize the teachers and students' online communication, but also can find the answer for the students who have the learning difficulties; What's more, it is important for teachers to solve the problem of lack of interaction in English listening test design.

In short, the application of ITS under the Moodle platform in the test of English listening in junior high schools for students is to create real listening learning situation, which deals with the problems of traditional listening test lack of interactivity and untimely feedback, and meets the requirements of students in English listening test, as well as makes the student have fully subjectivity in learning.

However, because the ITS is a frontier science research, and with the limited of writing space, so the author in the analysis exists many problems, and need continue research. We believe that with the development of education informationization, the Moodle platform based on ITS will be increasingly used in English listening to assist the designing of English listening test.

\section{ACKNOWLEDGMENT}

In the process of my study, would like to express my thanks to many people who give me support and guidance. Without their help, the study will not be successful.

First, I'd like to express my deepest gratitude to my advisor $\mathrm{Hu}$ Xianzhi, for his support and guidance throughout the research. He gives me helpful instruction, valuable suggestions and useful direction to help me with my structural arrangement, research analysis. Without his guidance and encouragement, the thesis would not come to fruition. 
At the same time, I would also like to extend my appreciation to other professors at Yibin University, especially to Professor Duan Zhigao, Professor Fan Jun, Professor Wang Yu. From their classes, I learn more professional knowledge about English learning and teaching, and my research ability improved. This will greatly benefit me in my future.

Finally, I would like to my parents and friends who give me encouragement and love throughout the process of my study. Also my best friend, Wang Yan, was always with me during the project.

\section{REFERENCES}

[1] Li Jing, Zhou Zhurong. The New Progress of Intelligent Toturing System. [J]. 2005(12):15

[2] Xu Gaopan, Zeng Wenhua. The Summary of Research on Intelligent Tutoring System[J]. Computer Application Research. 2009(11):4019

[3] Chen Shipin, Zhang Jianping. Research Hotspot and Development Trend of Intelligent Tutoring System[J]. E-education Research.2007(10):41
[4] Sun Ping. The Designing and Implementation of the Network Teaching Platform Based on Constructivism Theory[J]. Cumputer Knowledge and Technology. 2012(811): 2552

[5] Zhou Ping. "Listening Test Design and Teaching."Journal of Guangxi University 2.31(2009):6

[6] Chen Tianyun, Zhang Jianping. Research Status of Intelligent Tutoring System (ITS) and Its Development in China[J]. China E-education. 2007(241):96

[7] Xiao Yu. The Guiding Significace of Humanistic Learning Theory to Instructional Design[J]. Jurnal of Qiongzhou University. 2004(4)

[8] Zeng Zonggen. Moodle Network Course Platform[M]. No.205,Haidian District, Beijing:Peking University Press, 2010

[9] Zhong Jingjing. English Listening Teaching in Junior High School Based on Moodle Platform[D]. Jilin: Northeast Normal University,2011

[10] Tricia Hedge. Teaching and Learning in the Language Classroom [M]. Shanghai Foreign Language Education Press.2005

[11] Kathleen M. Bailey. Learning About Language Assessment: Dilemmas, Decisions and Directions [M].Foreign Language Teaching And Research Press. 200 